\title{
Running to Health, Sports and Medicine, A Winning Combination: Implementing Physical Activity to Fight Against Chronic Diseases
}

\section{Filomena Pietrantonio ${ }^{1^{*}}$ and Luca Traini ${ }^{2}$}

${ }^{1}$ Internal Medicine Unit Director, Manerbio Hospital, ASST Garda, Italy,

${ }^{2}$ Proposal Development Officer Save the Children Italia Onlus, Rome, Italy

\begin{abstract}
Background: Special knowledge in sports medicine inside Internal Medicine could enhance health and fitness preventing injuries and illnesses. Exercise role in promoting healthy lifestyle is essential to prevent most diseases through healthy lifestyle, including diet and lack of risky attitudes (smoking, alcohol) with early detection of age-related diseases. Moreover, according to the World Health Organization (WHO) disability classification ICF (International Classification of Functioning, Disability and Health) that adapt activities and environment to people's abilities, the interest towards physical activity (PA) adapted to health patients' status is increasing .

Methods: A 2014 pilot study on 157 athletes was performed to evaluate the impact of lifestyle on health administering a questionnaire (CRF) combining BMI, physical activity (weekly frequency per duration) and quality of food (evaluated considering the effect on metabolism and food combination). Results: 135 questionnaires were evaluated: M 76\%/F 21\%. 74\% of the sample showed regular BMI and $16 \%$ was overweight. Regular PA was performed by $84 \%$ and $69 \%$ considered good their dietary habits. PA benefits on health can be extended also to patients with chronic diseases (NCD) according to scientific consensus for a continuous dose-response relationship between PA and health benefits.

Conclusion: A correct lifestyle correlate with a better health status. Lower risks of cardiovascular disease have been observed with just 45-75 minutes of walking per week. The practice of Adapted Physical Activity for patient with disabilities due to NCD could be a valid starting point together with balanced diet for risk reduction in secondary prevention.
\end{abstract}

\section{Background}

Chronic diseases' impact on mortality and morbidity is growing worldwide. They are mainly due to cardiovascular diseases and cancer for the progressive reduction of problems related to predictable risks (particularly infective diseases) [1].

The epidemiological transition - the change of diseases' impact on health - has brought a considerable change in the international health context.

During the 20th century, heart disease, cancer, and other chronic conditions assumed more dominant roles, although outbreaks of infectious disease-from eastern equine encephalitis (1938) and kuru (1957) to legionnaires' disease (1977), AIDS (1981), and multidrugresistant tuberculosis (1993)-necessitated ongoing vigilance against microbes.

Regardless of the metric chosen, any map of the burden of disease expose disparities within and among populations. Two aspects of the burden of disease have remained particularly vexing: changes over time in the prevailing diseases and the persistence of health inequalities.

By examining the many new diseases that have appeared over the past two centuries, historians have categorized the ways in which diseases emerge. New causes (e.g., severe acute respiratory syndrome, motor vehicle accidents, radiation poisoning), new behaviors (cigarette smoking, intravenous drug use), and even the consequences of new therapies (insulin transforming the course and manifestations of diabetes) can produce new diseases. The interaction between the biologic and the social is equally apparent in the decline of a disease.
In this context appears of increasing interest the issue of Non Communicable Diseases (NCD) prevention with actions on lifestyle, diet, weight control, stop smoking and drinking alcohol [2,3].

To evaluate the potential impact of correct lifestyle on chronic diseases burden and progression an observational study was realized on a sample of athletes through the submission of a questionnaire in order to analyze the anthropometric data, diet, alcoholic and smoking habits and physical activity (PA). The athletes sample was choosen to observe a group of people surely committed to a correct lifestyle. We tried to extract a combined index (BMI plus diet plus PA) to be checked afterwards on patients with chronic diseases.

\section{Materials and Methods}

In order to assess the impact of lifestyle on Non Communicable Diseases burden a pilot study was conducted on an athletes sample during the Strafadoi races in Lazio region: The same questionnaire (CRF) was administered to a total of 157 athletes during 3 races in 2014. CRF was realized to identify, through a composite index, modifiable risk factors that cause NCD, and taking into account: weight, diet and physical activity. Weight was measured using Body Mass Index (BMI) according to the World Health Organization (WHO)

*Corresponding Author: Dr. Filomena Pietrantonio, Internal Medicine Unit Director, Manerbio Hospital, ASST Garda, Italy, Tel: +39 3291710748; Fax +39 065089501; E-mail: filomena.pietrantonio@gmail.com

Citation: Pietrantonio F, Traini L (2016) Running to Health, Sports and Medicine, A Winning Combination: Implementing PhysicalActivity to Fight Against Chronic Diseases. Int J Community Fam Med 1: 122. doi: https://doi.org/10.15344/2456$3498 / 2016 / 122$

Copyright: () 2016 Pietrantonio et al. This is an open-access article distributed under the terms of the Creative Commons Attribution License, which permits unrestricted use, distribution, and reproduction in any medium, provided the original author and source are credited. 
Citation: Pietrantonio F, Traini L (2016) Running to Health, Sports and Medicine, A Winning Combination: Implementing PhysicalActivity to Fight Against Chronic Diseases. Int J Community Fam Med 1: 122. doi: https://doi.org/10.15344/2456-3498/2016/122

Page 2 of 7

stratification, physical activity as weekly frequency and average activity duration. Foods were evaluated qualitatively enhancing their effect on metabolism and food combination.

\section{Questionnaire (CRF)}

The survey collected data, medical history, lifestyle, diet, diseases and treatment information about athletes. The research tool to define the nutritional status was a questionnaire containing items listed in Table 1.

The questionnaire was administered before 3 races held in Lazio during 2014: Strafadoi, Caffarella Cross, Per Antiqua Itinera races with the collaboration of the race organization committee and a preventive increased awareness on the lifestyle issue among the participants.

1) General information $\square$ age, sex;

2) Socio-economic data a income, job, type of activity, employment sector;

3) Clinical features a weight, height, abdominal circumference, blood pressure, heart rate;

4) Dietary habits;

5) Individual perception of lifestyle and dietary habits effects on health;

6) Anthropometric data o BMI;

7) Diseases and drugs or other treatment.

Table 1: CRF items.

\section{Results}

The administered questionnaires were 157, evaluated 135. Male: $76 \%$ and female $21 \%$ (table 2); mean age was 43,5 years; BMI was regular in $74 \%$ of the sample, $16 \%$ was overweight and $4 \%$ underweight . Regular physical activity was performed by $84 \%$ of the sample and $34,48 \%$ was performing PA every day. The athletes sample was constituted by middle-aged (46 years average) and employed people $(85 \%)$ and only $9 \%$ retired. The nutrition habits were considered good by the majority of the sample (69\%) (table 3).Only 3\% of the sample was taking pharmacological treatment. (The results are shown in figures from 1 to 6 ).

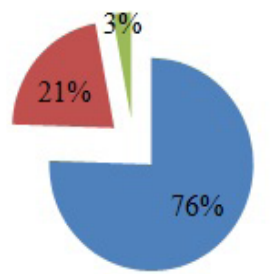

- Men

- Women

Unknown

Figure 1: General information: Sex.

Body Mass Index

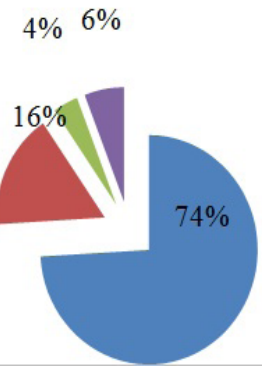

Normal range

Overweight

Underweight

Unknown

1.

Figure 2: BMI (Body Mass Index).

\begin{tabular}{|l|l|l|}
\hline General information & 102 & $76 \%$ \\
\hline Men & 29 & $21 \%$ \\
\hline Women & 4 & $3 \%$ \\
\hline Unknown & 46,57 & $0 \%$ \\
\hline Mean age & \multicolumn{2}{l|}{} \\
\hline Job & 115 & $85 \%$ \\
\hline Employed & 12 & $9 \%$ \\
\hline Retired & 8 & $6 \%$ \\
\hline Other (unemployed, student, unknown) & \multicolumn{2}{|l|}{} \\
\hline Do you consider good your diet? & 93 & $69 \%$ \\
\hline Yes & 28 & $21 \%$ \\
\hline No & 14 & $10 \%$ \\
\hline Unknown & 93 \\
\hline
\end{tabular}

Table 2: Sinoptic table of sample characteristics.

\begin{tabular}{|c|c|c|}
\hline \multicolumn{3}{|l|}{ Do you practice sport regularly? } \\
\hline Yes & 113 & $84 \%$ \\
\hline No & 5 & $4 \%$ \\
\hline Unknown & 17 & $13 \%$ \\
\hline \multicolumn{3}{|c|}{ How many times do you practice sport per week? } \\
\hline Almost every day (6/7 days) & 33 & $24 \%$ \\
\hline Some days ( $3 / 4 / 5$ days) & 83 & $61 \%$ \\
\hline Few days/Week end ( $1 / 2$ days) & 2 & $1 \%$ \\
\hline Unknown & 17 & $13 \%$ \\
\hline \multicolumn{3}{|l|}{ Body Mass Index } \\
\hline Normal range & 100 & $74 \%$ \\
\hline Overweight & 22 & $16 \%$ \\
\hline Underweight & 5 & $4 \%$ \\
\hline Unknown & 8 & $6 \%$ \\
\hline
\end{tabular}

Table 3: Items related to healthy status.

Employment

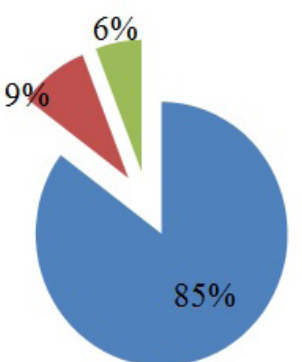

Figure 3: Employment.

Do you consider good your diet?

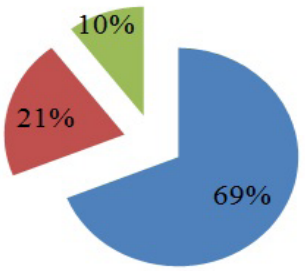

- Yes No

Unknown

口

Figure 5: Regularly exercise. 


\section{How many times do you practice sport per week?

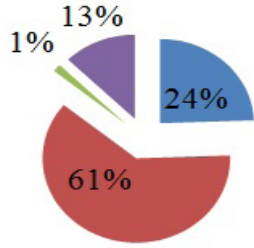

$$
\begin{aligned}
& \text { Almost every day } \\
& \text { (6/7 days) } \\
& \text { Some days }(3 / 4 / 5 \\
& \text { days) } \\
& \text { Few days/Week } \\
& \text { end ( } 1 / 2 \text { days) }
\end{aligned}
$$

Figure 6: Weekly activity.

\section{Discussion}

In 1859 Charles Darwin suggested with the evolution theory that fitness was critical in the evolution of the species.

A recent article published in the New England Journal of Medicine [4] underlines the correlation between lifestyle and dietary habits, and morbidity and mortality due to chronicle diseases.

Risk factors such as smoking, alcohol consumption, excess weight, and dietary factors are responsible for a large share of the global disease burden, directly or through conditions such as high blood pressure and elevated blood glucose and cholesterol levels [5].

Being physically active is one of the most important steps that Americans can take to improve their health. The 2008 Physical Activity Guidelines for Americans recommends that adults participate in at least 2 hours and 30 minutes ( 150 minutes) a week of moderateintensity aerobic physical activity and at least two or more times a week of muscle-strengthening activities for health benefits. For additional and more extensive health benefits, adults should increase their aerobic physical activity to 300 minutes (5 hours) a week of moderate intensity[6].Children and adolescents should practice 1 hour (60 minutes) or more of physical activity daily.

People who are physically active generally live longer and have a lower risk for heart disease, stroke, type 2 diabetes, depression, and some cancers. Physical activity can also help control weight. However, only about half of adults and less than a third of youth meet aerobic physical activity guidelines[7].

Chronic Diseases are strongly connected to lifestyle, especially the use of tobacco, unhealthy diet habits, physical inactivity, and psychosocial stress. The World Health Organization (WHO) has stated that over three-quarters of all cardiovascular mortality may be prevented with adequate changes in lifestyle. Chronic Diseases prevention, remaining a major challenge for the general population, politicians, and healthcare workers alike, is defined as a co-ordinated set of actions, at public and individual level, aimed at eradicating, eliminating, or minimizing the impact of Chronic Diseases and their related disability. The bases of prevention are rooted in epidemiology and evidence-based medicine and has to be promoted by Internal Medicine Specialists as a starting point in the treatment of Chronic Diseases[8]. Table 4 shows the factors that affects longevity.

In 2011 FADOI (Federazione delle Associazioni di Medicina Interna Ospedaliera) conducted a retrospective study in partnership with ISS (Istituto Superiore di Sanità) that highlighted the possible positive effect of physical activity among 20-40 years old people as primary prevention of cardiovascular events.

\begin{tabular}{|l|l|}
\hline Factors that affect longevity [9]. & \\
\hline Lifestyle & $50 \%$ \\
\hline Environment & $20 \%$ \\
\hline Genetic heritage & $20 \%$ \\
\hline Healthcare & $10 \%$ \\
\hline $\begin{array}{l}\text { B. Bodura. Scientific foundations for a public health policy in } \\
\text { Europe. Juventa, Weinheim, 1995: 364 (mod) }\end{array}$ \\
Table 4: Factors that affect longevity.
\end{tabular}

The study involved 2191 patients between 65 and 75 years that were hospitalized in Internal Medicine ward: data were collected from medical records and patients' history.

Then, in order to evaluate physical activity, the research team submitted questionnaires about physical activity, sedentary level of work, spare time and daily routine.

Results shows that $44,2 \%$ of patients have conducted moderate/ intense physical activity between 20 and 40 years old. 35,8\% have had at least a relevant cardiovascular problem, while the tendency of cardiovascular disease is slightly lower for patients with good physical activity history (average risk decrease: $4 \%$ with multivariate analysis) Most relevant positive effects have been found in diabetic patients: based on the multivariate analysis, those who had an active life have $24 \%$ lower cardiovascular disease risk than those who had a sedentary life [10].

International Classification of Functioning, Disability and Health (ICF) and Adapted Physical Activity (APA). ICF was approved by the World Health Assembly on May 22, 2001[11] and has changed the point of view of considering disability. Functioning and disability are viewed as a complex interaction between the health condition of the individual and the contextual factors of the environment as well as personal factors. All aspects of a person's life (development, participation and environment) are incorporated into the ICF instead of solely focusing on his or her diagnosis. Diagnoses are important for defining the cause and prognosis, but identifying the limitations of function is often the information used to plan and implement interventions[12]. Once a rehabilitation team is aware of the daily activities, a client is required to participate in, the problem solving sequence set up by the ICF can be utilized[13]. Following ICF principles, the Adapted Physical Activity (APA) )[14] was introduced as exercise programs addressed to groups of persons with chronic diseases that deduce physical capacity, in order to modify lifestyle and strengthen secondary and tertiary prevention of disabilities. Adult/ elderly citizen with low disability can start with Adopted Physical Activity (APA) upon medical advice while those with high disability need a preliminary physiatrist evaluation.

\section{Conclusions}

The study performed on an athletes sample showed the benefits of PA on health. The majority of the sample showed a normal BMI, correct dietary habits and no need of pharmacological treatment. Exercise is one of the mainstay clinical interventions for the prevention and treatment of cardiovascular diseases. Not only, exercise reduce cardiovascular risk factors, such as diabetes mellitus and hypertension, 
Citation: Pietrantonio F, Traini L (2016) Running to Health, Sports and Medicine, A Winning Combination: Implementing PhysicalActivity to Fight Against Chronic Diseases. Int J Community Fam Med 1: 122. doi: https://doi.org/10.15344/2456-3498/2016/122

Page 4 of 7

thereby helping to prevent heart disease, it also appears to improve the functional status and outcomes in patients with existing heart disease. The cardiovascular benefits of exercise are multifactorial, and include important systemic effects on skeletal muscle, peripheral vasculature, and metabolism, as well as beneficial alterations within the myocardium itself [15]. Exercise is perhaps one of the cheapest and most effective-interventions for reducing the morbidity and mortality of cardiovascular disease[16. In fact, as little as 45 to 75 minutes of brisk walking each week appears to reduce the relative risk for adverse cardiac events $[17,18,19]$. The preliminary results of this study suggest that increasing physical activity could prevent the burden of NCD, acting on primary prevention and even in patients with disabilities due to NCD Adapted Physical Activity could be a valid starting point together with balanced diet for risk reduction in secondary prevention.

\section{Competing Interests}

The authors declare that they have no competing interests.

\section{References}

1. Jones DS, Podolsky SH, Greene JA (2012) The burden of disease and the changing task of medicine. N Engl J Med 366: 2333-2338.

2. Centers for Disease Control and Prevention (2013) Adult Participation in Aerobic and Muscle- Strengthening Physical Activities-United States, 2011. Morb Mortal Wkly Rep 62: 326-330.

3. Centers for Disease Control and Prevention (2012) Youth Risk Behavior Surveillance, United States, 2011. Morb Mortal Wkly Rep, pp. 611-28.

4. Ezzati M, Riboli E (2013) Behavioral and dietary risk factors for noncommunicable diseases. N Engl J Med 369: 954-964.

5. Lim SS, Vos T, Flaxman AD, Danaei G, Shibuya K, et al. (2012) A comparative risk assessment of burden of disease and injury attributable to 67 risk factors and risk factor clusters in 21 regions, 1990-2010: systematic analysis for the Global Burden of Disease Study 2010. Lancet 380: 2224-2260.

6. Centers for Disease Control and Prevention (CDC) (2008) Prevalence of self-reported physically active adults--United States, 2007. MMWR Morb Mortal Wkly Rep 57: 1297-1300.

7. Physical Activity Guidelines Advisory Committee (2008) Physical Activity Guidelines Advisory Committee Report, 2008. In: U.S. Department of Health and Human Services, editor. Washington, DC.

8. Chronic Diseases and health promotion.

9. B Bodura (1995) Scientific foundations for a public health policy in Europe. Juventa, Weinheim, pp. 364

10. Cipollini F, Gussoni G, Pacifici R, Rossi S, Bonizzoni E, et al. (2011) The influence of physical activity performed at 20-40 years of age on cardiovascular outcomes in medical patients aged 65-75. Italian Journa of Medicine 5: 114-119.

11. http://www.cdc.gov/nchs/about/otheract/icd9/icfhome.html

12. Lollar DJ, Simeonsson RJ (2005) Diagnosis to function: classification for children and youths. J Dev Behav Pediatr 26: 323-330.

13. Bornman J (2004) The World Health Organisation's terminology and classification: application to severe disability. Disabil Rehabil 26: 182-188.

14. De Francesco. Esercizio fisico adattato...e dintorni! Una nuova frontiera per la Medicina dello Sport. Casa Editrice Scientifica Internazionale (ESI), 2016.

15. Mann N, Rosenzweig A (2012) Can exercise teach us how to treat heart disease? Circulation 126: 2625-2635.

16. Booth FW, Gordon SE, Carlson CJ, Hamilton MT (2000) Waging war on modern chronic diseases: primary prevention through exercise biology. $J$ Appl Physiol 88: 774-787.
17. Manson JE, Greenland P, LaCroix AZ, Stefanick ML, Mouton CP, et al. (2002) Walking compared with vigorous exercise for the prevention of cardiovascular events in women. N Engl J Med 347: 716-725.

18. Haskell WL, Lee IM, Pate RR, Powell KE, Blair SN, et al. (2007) Physical activity and public health: Updated recommendation for adults from the American College of Sports Medicine and the American Heart Association. Med Sci Sports Exerc 39: 1423-1434.

19. Nelson ME, Rejeski WJ, Blair SN, Duncan PW, Judge JO, et al. (2007) Physical Activity and Public Health in Older Adults Recommendation From the American College of Sports Medicine and the American Heart Association. Circulation 116: 1094-1105. 